\title{
CDISC SDTM Nervous System Physiology Test Code Terminology
}

National Cancer Institute

\section{Source}

National Cancer Institute. CDISC SDTM Nervous System Physiology Test Code

Terminology. NCl Thesaurus. Code C116104.

Terminology associated with the nervous system physiology test code codelist of the Clinical Data Interchange Standards Consortium (CDISC) Study Data Tabulation Model (SDTM). 